\title{
Stratified turbulence and small-scale internal waves above deep-ocean topography
}

\author{
Hans van Haren ${ }^{a)}$ \\ Royal Netherlands Institute for Sea Research (NIOZ), P.O. Box 59, \\ 1790 AB Den Burg, The Netherlands
}

(Received 17 May 2013; accepted 11 October 2013; published online 30 October 2013)

\begin{abstract}
When ocean's internal tidal waves "beach" at underwater topography, they transform from more or less linear into highly nonlinear waves that can break with generation of vigorous turbulent mixing. Although most mixing occurs in the half hour around a steep (bottom-)front leading the upslope moving internal tide phase, relatively large mixing also occurs some distance of several tens of meters off the bottom, just prior to the downslope moving internal tide phase and initiated by highfrequency "small-scale" internal waves. Details of this off-bottom small-scale mixing in a stratified natural environment and some of its variability per tidal period are presented here in two case studies using high-resolution temperature observations (61 sensors at $1 \mathrm{~m}$ intervals; $<10^{-3}{ }^{\circ} \mathrm{C}$ precision) at a $969 \mathrm{~m}$ deep site south of New Zealand. The observations shed some light on stratified turbulence that is generated in a relatively thick $(\sim 30 \mathrm{~m})$ weakly stratified layer and in the strongly stratified interfaces above and below. The interfacial internal waves generate turbulence with largest dissipation rate and temperature variance at the edge of the upper interface and the weakly stratified layer. When these waves steep nonlinearly, immediate moderate turbulence generation is observed below, throughout the weakly stratified layer. Largest turbulence is generated by $25 \mathrm{~m}$ high asymmetric Holmboe overturns. (c) 2013 AIP Publishing LLC. [http://dx.doi.org/10.1063/1.4826888]
\end{abstract}

\section{INTRODUCTION}

The ocean can be considered as a huge hydrodynamics laboratory. Especially wave breaking, high Reynolds number flows, and stratified turbulence processes are omnipresent above its sloping bottom topography. Such omnipresence at a wide range of scales is hard to obtain in flumes in a standard laboratory. However, observational studies in the ocean have their own difficulties, viz., the enormous static pressure (every $10 \mathrm{~m}$ depth pressure increases by $10^{5} \mathrm{~Pa}$ ) and the ocean's vastness being just two of them. Another problem in the ocean is the use of self-contained instrumentation, with pressure vessels protecting electronics including data storage and power supply. In contrast with fluid mechanics studies in man-made laboratories under controllable circumstances, studies in the ocean are mainly performed with black-boxes. In the ocean, no parameter tuning is possible during the experiment, except when connected to a (rare) cabled network. This results in rather lengthy (repeated) experiments in time and a relatively slow progress in development of instrumentation. However, with the advance of modern electronics some progress can be made to study fluid mechanics processes in the ocean, from both the perspective of a hydrodynamicist and that of an oceanographer.

One of the outstanding problems in oceanography is the study of turbulent exchange across the stable vertical density stratification. This exchange is relevant for the ocean's life, as it constitutes a major means of transporting (fluxing) of nutrients into the photic zone. It is also important for the redistribution of materials in general, sediment in particular. One of the major contributors to

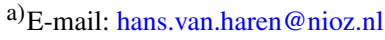


the mechanical generation of turbulence in the ocean is the breaking of "internal" waves. ${ }^{1}$ Such waves are supported by the ocean's stratification in density from surface to bottom. The associated restoring force is about a thousand times smaller than that for surface waves, commensurate the much smaller vertical density differences compared to the density difference between air and water. It results in tens of meters high internal wave amplitudes and an ocean which is permanently in "wave motion."2,3 Typical internal wave periods range from one day (at mid-latitudes) to one hour, in the deep ocean, and a few minutes, near the ocean surface. Typical (internal-wave-generated) turbulence scales vary from several tens of meters, the internal wave height and the buoyancy scale, to a few millimeters, the dissipation scale. In time, turbulence scales range from $10^{-2}$ to $10^{3} \mathrm{~s}$. In the open ocean, internal waves are ubiquitous causing permanent motion ${ }^{2,4}$ but their turbulence generation is relatively weak. ${ }^{1,5}$ It seems that most turbulence is generated where internal waves "beach," at underwater topography. This has been discussed theoretically over quite some time, ${ }^{6-8}$ but quantitative observational evidence is rather sparse of internal wave induced turbulence. ${ }^{3}$

One of the reasons for this limited observational evidence is that density (variations) cannot be measured directly. As density is determined (for more than 99\%) by temperature $\mathrm{T}$ and salinity S (variations), as a function of pressure it suffices to measure one of these quantities, under certain conditions. Of these two, the measurement of salinity is most difficult, as it is done indirectly via conductivity, which itself is highly temperature dependent. This results in a relatively large noise level compared to the measurement of temperature. However, one could refrain from salinity measurements under the condition of a tight (linear, persistent with time) T-S relationship. Such a relationship holds in surprisingly many ocean areas although not in all and not always.

Ideally, one would like to measure temperature covering all internal wave turbulence scales, at sufficient precision. Presently, this is impossible, but some progress has been made by the construction of high sampling-rate thermistors. ${ }^{2,9,10}$ Initially, 1-Hz sampling-rate thermistors could only be used in a towed fashion cabled to a ship, ${ }^{2}$ but modern electronics allow stand-alone sensors that can operate uninterruptedly for a period of a year. ${ }^{10}$ When many are used, say 100 at $1 \mathrm{~m}$ intervals, time-depth images can be obtained that resolve internal waves and the larger, most energetic turbulence scales, provided the sensors' noise level and precision are sufficiently small (typically $0.001{ }^{\circ} \mathrm{C}$ or less). The advantage of measuring temperature over even better spatially resolving acoustics is that the former can quantify the associated turbulence, ${ }^{11}$ whereas the latter can only provide qualitative, quasi-synoptic images due to calibration problems. (Nonetheless, such shipborne acoustic images demonstrate very detailed overturning including secondary turbulence along the rim of the largest Kelvin-Helmholtz overturn in high Reynolds number flows in shallow seas). ${ }^{12-14}$

In the present paper, case-studies are presented of particular stratified-turbulence close to, but some distance above, deep underwater topography south of New Zealand. One day, two tidal periods, of high-precision temperature sensor data are used to demonstrate spatial and temporal variability and the importance of high-frequency interfacial internal waves. It is demonstrated that in an (internal wave) sheared environment such waves can develop turbulence along the interfaces and in the weaker stratified layers they surround, but asymmetrically mainly. Rare ocean examples are provided of (asymmetric) Holmboe overturns, which can develop in areas where the thickness of the shear layer is larger than the thickness of the density interface. ${ }^{15,16}$ These instabilities, initiated by two waves propagating above and below an interface with opposing phase speeds, grow slower than their better known Kelvin-Helmholtz instabilities. Yet, it is conjectured from numerical simulations ${ }^{15}$ that their contribution to diapycnal exchange is approximately equal, as the high mixing efficiency is maintained over a longer period during the slower Holmboe development. The presented observations may be compared with DNS and laboratory studies, ${ }^{16-18}$ for the specific case when the centres of the shear and density interfaces are vertically displaced with respect to each other. This results in asymmetric Holmboe overturning, or cusping, into the weaker stratified layer.

\section{MATERIALS AND METHODS}

A taut-wire mooring was deployed from 10 to 15 April 2011 at $41^{\circ} 44.544^{\prime} \mathrm{S}, 175^{\circ} 27.177^{\prime} \mathrm{E}, \mathrm{H}$ = $969 \mathrm{~m}$ water depth of Opouawe Bank, Hikurangi Margin, New Zealand (Figure 1). A total of 61 


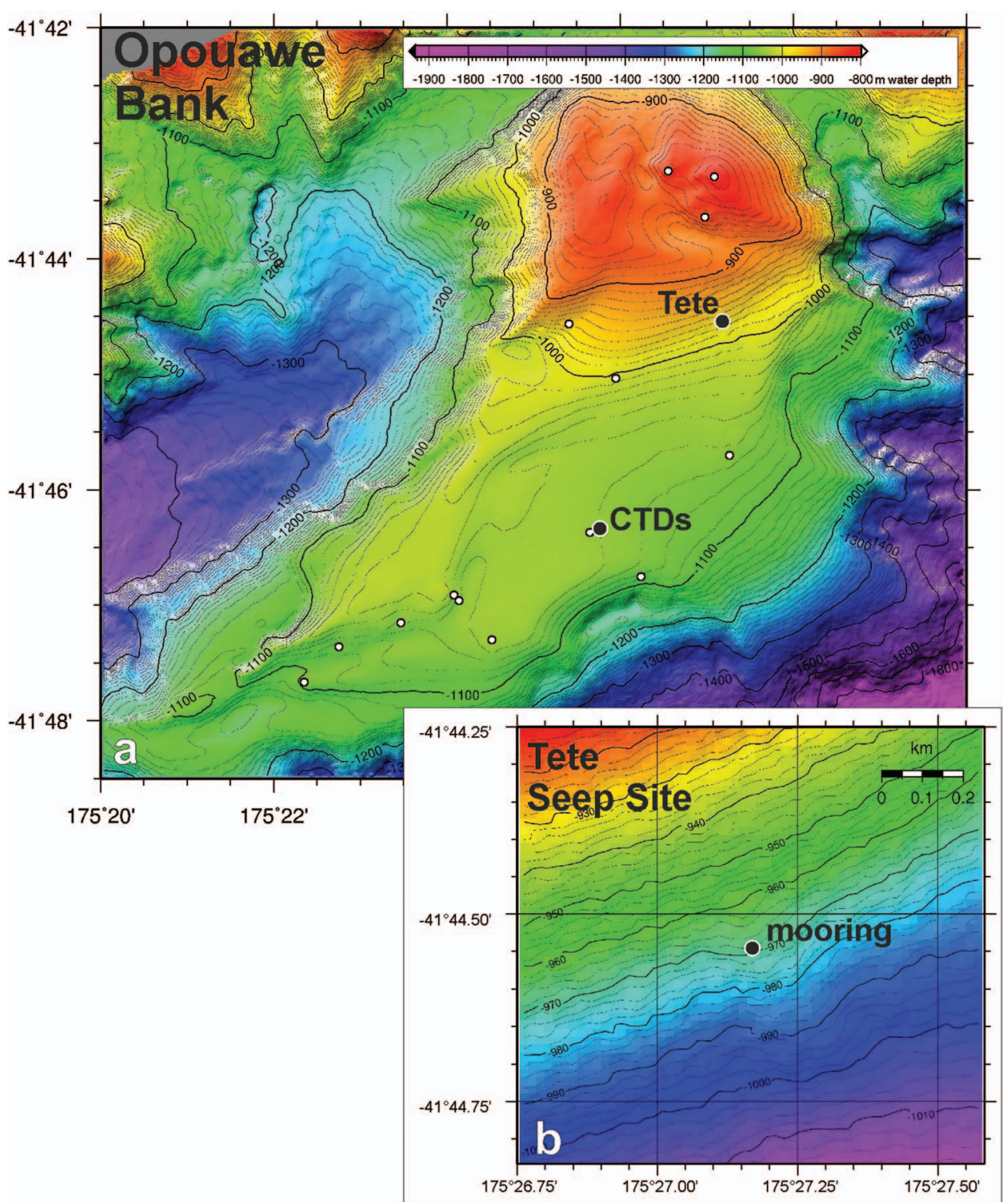

FIG. 1. (a) Opouawe Bank mooring area to the southeast of New Zealand, northern island. This relatively deep bank is an area with many known methane gas seeps (open circles), of which mooring area Tete (b) is on a southward dipping slope. Note the color levels are different from those in Figure 1(a). Water depth is indicated by the contour lines.

"NIOZ4" self-contained temperature (T) sensors were taped at $1.0 \mathrm{~m}$ vertical intervals to a nyloncoated steel cable, with the lowest sensor $7 \mathrm{~m}$ above the bottom and the upper sensor about $2.5 \mathrm{~m}$ below a single elliptic buoy. Sampling rate was $1 \mathrm{~Hz}$, with precision better than $0.001{ }^{\circ} \mathrm{C}$ and a noise level of about $6 \times 10^{-5}{ }^{\circ} \mathrm{C}$. NIOZ4 is an upgrade of NIOZ3, ${ }^{10}$ with similar characteristics, except for its reduced size ( $2 / 3$ smaller) and reduced power consumption (with the capacity of sampling at a rate of $2 \mathrm{~Hz}$ for the duration of 1 year). The sensors were synchronized via induction every $6 \mathrm{~h}$, so that timing mismatch was $<0.04 \mathrm{~s}$.

The multi-beam bathymetry of Figure 1 is used to compute local bottom slopes. ${ }^{19}$ Around the mooring, the mean slope was $\gamma=0.094\left(5.4^{\circ}\right)$. Using local CTD observations to determine a "mean" large-scale buoyancy frequency $\mathrm{N}=(3 \pm 1) \times 10^{-3} \mathrm{~s}^{-1}$, this bottom-slope is compared with internal wave ray slopes $\beta=\sin ^{-1}\left(\left(\sigma^{2}-\mathrm{f}^{2}\right)^{1 / 2} /\left(\mathrm{N}^{2}-\mathrm{f}^{2}\right)^{1 / 2}\right)$, for wave $(\sigma)$ and inertial (f) frequencies in an environment of constant $\mathrm{N}$. The $100-\mathrm{m}$ vertical averaging scale of this mean buoyancy is adequate 
to resolve the height (twice the amplitude) of the largest internal waves. It is thus equivalent to averaging over other large internal wave scales: $1-10 \mathrm{~km}$ in the horizontal and one day in time. For the dominant semidiurnal lunar tidal frequency $\mathrm{M}_{2}$ a mean $\beta=0.034 \pm 0.011\left(1.9^{\circ} \pm 0.6^{\circ}\right)$ is found, so that $\gamma>\beta$, or super-critical for internal tides, significant to within $95 \%$ uncertainty. Critical slopes are found about a kilometer, or one internal tide wavelength, both to the north and to the south of the mooring. ${ }^{19}$

No current meters were attached to the present mooring. Current data from previous moorings nearby ${ }^{20,21}$ indicate tidal amplitudes of $0.2-0.25 \mathrm{~m} \mathrm{~s}^{-1}$, with major axis more or less perpendicular to the large-scale topographic isobaths.

Temperature sensor data are first transferred to conservative temperature $(\Theta)$ values, ${ }^{22,23}$ before they are used as an estimate for (variations in) potential density anomaly referenced to a level of $1000 \mathrm{dBar}\left(\sigma_{1000}\right)$ following a reasonably tight, constant linear relationship obtained from nearby shipborne Conductivity-Temperature-Depth (CTD) profiles, $\delta \sigma_{1000}=\alpha \delta \Theta$, where $\alpha=-0.15 \pm$ $0.01 \mathrm{~kg} \mathrm{~m}^{-3}{ }^{\circ} \mathrm{C}^{-1}$ is the thermal expansion coefficient under local conditions. This relationship is a mean for the lower $100 \mathrm{~m}$ above the bottom for five CTD-profiles near the mooring site. ${ }^{19}$ The above "tight" mean relationship is used to estimate turbulence parameters from the moored temperature sensor data. Care is taken to recognize layers of temperature inversions that might be over-compensated by salinity as these give false turbulent overturning information. Few such inversions exist in the one day of observations presented here and they are relatively easily visually detectable in detailed turbulence parameter images (see below).

The CTD-data indicate that the large-scale $(\Delta \mathrm{z}=100 \mathrm{~m})$ buoyancy frequency $\mathrm{N}$ supports internal waves having periods down to $\mathrm{T}_{\mathrm{N}}=1500 \mathrm{~s}$. In detail, small-scale $\Delta \mathrm{z}=1 \mathrm{~m}$ indicates that around density interfaces a maximum buoyancy frequency is found of $\mathrm{N}_{1, \max } \equiv \mathrm{N}_{\mathrm{m}}=10^{-1.7} \mathrm{~s}^{-1}$ or a minimum small-scale internal wave period down to $\mathrm{T}_{\mathrm{Nm}}=300 \mathrm{~s}$.

Turbulent kinetic energy dissipation rate $\varepsilon$ (and vertical turbulent eddy diffusivity $\mathrm{K}_{\mathrm{z}}$ ) are estimated in a classic oceanographic method by calculating "overturning" scales using $\alpha \delta \Theta$-data. These scales are obtained after sorting every $1-\mathrm{Hz}$ time-step potential density (temperature) profile, which may contain inversions, into a stable monotonic profile without inversions. ${ }^{9,24}$ This method assumes that overturns have turbulent kinetic energy which is proportional to available potential energy and that this energy is dissipated within a buoyancy period. After comparing raw and sorted profiles, displacements (d) are calculated necessary for generating the stable profile. A certain threshold applies to disregard apparent displacements associated with instrumental noise in the case of temperature (density) profiles obtained from CTD. ${ }^{25}$ In our case, temperature profiles are obtained from a set of 61 independent sensors and the limiting factor for a threshold is not instrumental noise (which is very low, see above), but rather the remaining temperature-shifts after calibration $(<5 \times$ $\left.10^{-4}{ }^{\circ} \mathrm{C}\right) .{ }^{10}$ Then we estimate

$$
\varepsilon=0.64 \mathrm{~d}^{2} \mathrm{~N}^{3},
$$

where $\mathrm{N}$ denotes the buoyancy frequency computed from the reordered profile and the constant follows from empirically relating the overturning scale with the Ozmidov scale $\mathrm{L}_{\mathrm{O}}=0.8 \mathrm{~d}$. $^{26}$ Using $\mathrm{K}_{\mathrm{z}}=\Gamma \varepsilon \mathrm{N}^{-2}$ and a mixing efficiency for the conversion of kinetic into potential energy of $\Gamma=0.2,{ }^{27,28}$ we find

$$
\mathrm{K}_{\mathrm{z}}=0.128 \mathrm{~d}^{2} \mathrm{~N} .
$$

The above estimate of turbulence dissipation rate is compared with high-frequency (arbitrary cut-off at $0.02 \mathrm{~Hz}$ ), turbulence temperature variance. Although a different turbulence frequency range is used here given the different sampling rates, the computation of such variance has similarities with the computation of higher-frequency conductivity variance used for estuarine data ${ }^{13}$ and the computation of temperature dissipation rate that was compared with kinetic energy dissipation rates in the upper ocean. ${ }^{28}$ Here, the temperature variance is scaled with the local buoyancy frequency, which follows after relating isopycnals excursions, which are indicative of potential energy, to $\mathrm{L}_{0}{ }^{36}$

In the following, averaging over time is denoted by [...], averaging over depth-range by $\langle\ldots\rangle$. The specific averaging periods and ranges are indicated with the mean values. 


\section{OBSERVATIONS}

Approximately a single day of temperature observations shows two internal tidal waves of 50-60 m crest-trough height (Figure 2(a)). The waves are quite nonlinear, with a steep front of the upslope (cooling) phase and a gradual downslope (warming) phase. The internal tide is superposed with higher-frequency internal waves, especially after the front during the upslope phase. Of these, the most obvious, about half-an-hour-period waves have heights of 10-30 m. The downslope tidal phase seems smoother, but also shows higher frequency internal waves, at even shorter periods of some $600 \mathrm{~s}$.

The vertically averaged, i.e., more or less tidal-wave-height-averaged, turbulence dissipation rates vary over 3-4 orders of magnitude during a tidal cycle (Figure 2(b) black graph; note the logarithmic scale). Averaged over the $25 \mathrm{~h}$ and the $60 \mathrm{~m}$ range, the depth-time mean dissipation rate amounts $[\langle\varepsilon\rangle]=(1 \pm 0.3) \times 10^{-7} \mathrm{~W} \mathrm{~kg}^{-1}$ (and the associated vertical eddy diffusivity $\left[\left\langle\mathrm{K}_{\mathrm{z}}\right\rangle\right]=(2$ $\left.\pm 0.7) \times 10^{-3} \mathrm{~m}^{2} \mathrm{~s}^{-1}\right) \cdot{ }^{19}$ These values are about 100 times larger than open ocean values. About half of the turbulent mixing occurs in less than half an hour around the front passage of the upslope phase (around days 102.01 and 102.48). Note that the frontal passages are not, necessarily, an exact tidal period apart ( $=0.52$ day for a lunar tide), which is associated with the "intermittent" nature so typical for internal tidal waves. ${ }^{29}$ During the course of a tidal period, turbulence decays after the front. However, the apparent peaks also later in the tidal phase in Figure 2(b) are not artificial spikes, but turbulence produced by short-term "internal wave breaking." Some of these will be detailed below.

The vertically averaged, $\mathrm{N}$-scaled high-frequency (HF), turbulence temperature variance (Figure 2(b), green) shows a similar internal tide, and more or less similar higher frequency

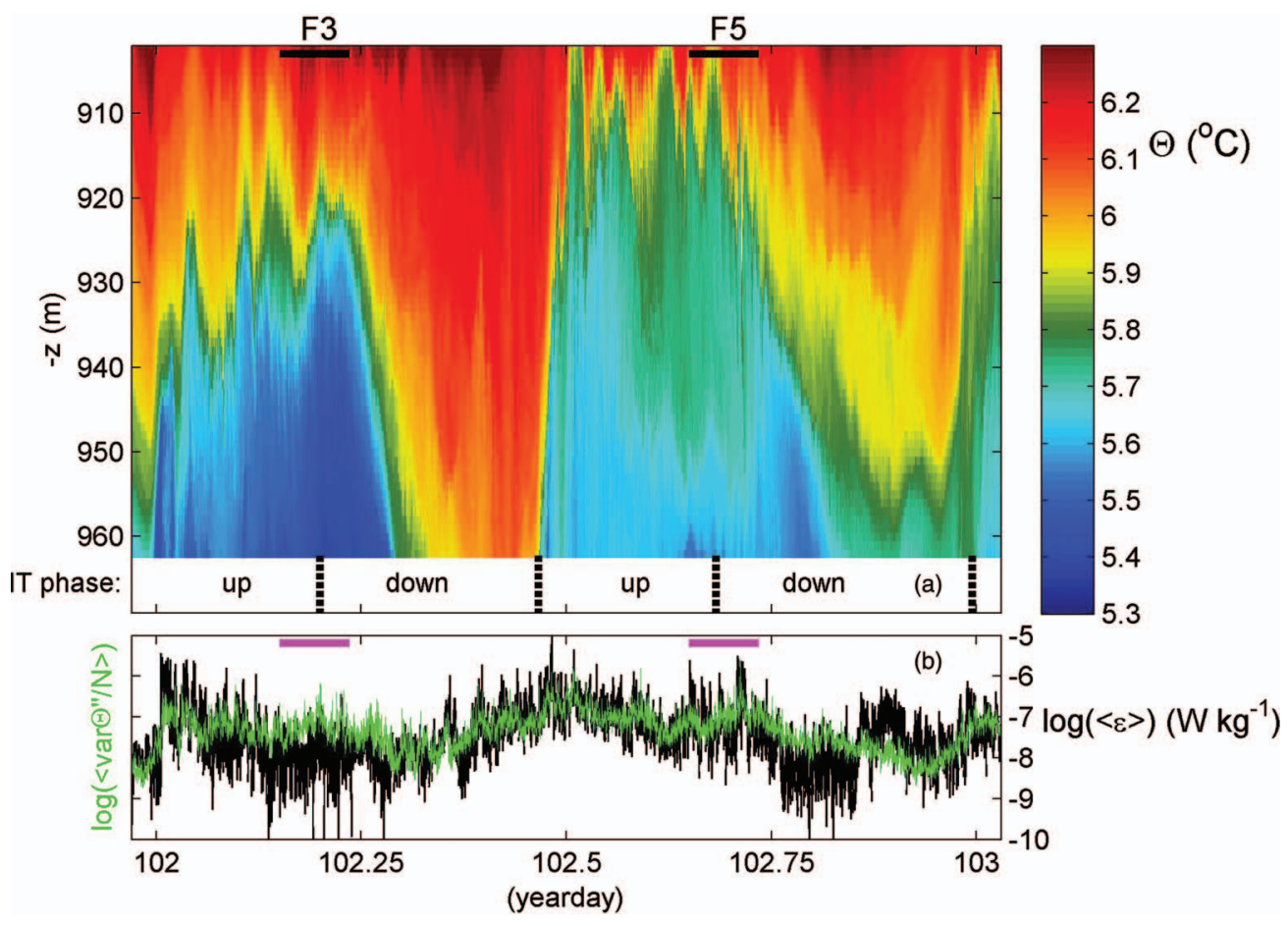

FIG. 2. Two tidal periods of internal wave motions measured by 61 high-sampling rate thermistors between 7 and $67 \mathrm{~m}$ above a sloping bottom south-west of Northern Island, New Zealand. (a) Depth-time series of observed conservative temperature. The periods of one-and-a-half-hour detail figures (indicated by letter F and their figure number) around the turn of the tide are indicated above the panel. Up- and downslope phases of the internal tide are indicated in the bottom. (b) Time series of logarithm of vertically averaged dissipation rate inferred from the data in (a) using the sorting method of Ref. 24 . These are compared with time series of logarithm of high-frequency (cut-off at $0.02 \mathrm{~Hz}$ ) temperature variance, scaled with local buoyancy frequency and averaged over the entire vertical range of sensors (arbitrary vertical scale). 
internal wave, variability as the estimated dissipation rates (Figure 2(b), black). The HF-temperature variance amplitude is slightly smaller, while the two time series show a correlation of about $60 \%$. In detail, the two may vary, but generally they indicate the same periods of high and low turbulent mixing, including peaks around the change of internal tide phases.

One of the short-term turbulence peaks occurs during the turn of the tide, also just prior to the downslope phase. Occasionally, in this case during the second tidal period, the turbulent dissipation rate due to "small-scale" wave breaking at the start of the downslope internal tide phase is nearly as large as the one associated with the upslope front. During most tidal periods, the "background" dissipation rate rises prior to the start of the downslope phase (see also data from a different area in Ref. 30; not resolved $\sim 100 \mathrm{~m}$ high tidal wave).

In detail, such a common end of the upslope phase shows a strongly stratified thin interface tens of meters above the bottom, overlying a thick weakly stratified layer (Figure 3(a)). This weakly stratified layer does not represent a bottom boundary layer because (i) it overlies a relatively strongly stratified thin interface closer to the bottom (partially visible in Figure 3(b), better in Figure 5(b); recall that the lowest sensor was $7 \mathrm{~m}$ above the bottom) and (ii) it is not homogeneous, but stratified in interfaces that are tilted from the vertical (Figure 3(b)). As expected, largest overturning is observed in the weakly stratified layer. Variations are also observed within that layer, and there

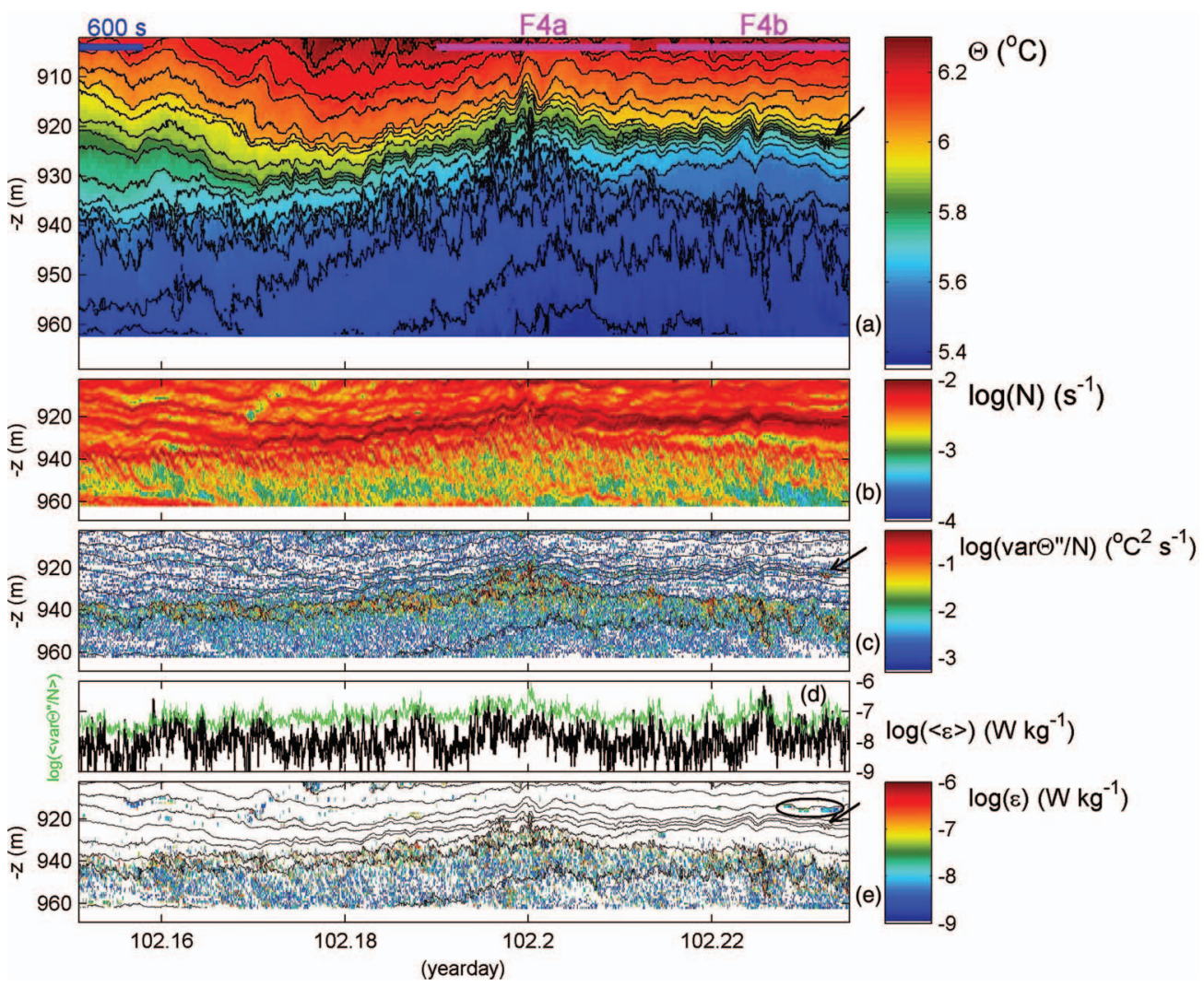

FIG. 3. One-and-a-half-hour sample detail from Figure 2 in which relatively small high-frequency internal wave activity is observed during the change in internal tide phase from upslope cooling to the downslope warming. (a) Observed conservative temperature, with contours every $0.05^{\circ} \mathrm{C}$. (b) Stable stratification after sorting (a) to stable profiles every time step and using $\delta \sigma_{1000}=-0.15 \delta \Theta \mathrm{kg} \mathrm{m}^{-3}{ }^{\circ} \mathrm{C}^{-1}$ (see text). (c) High-frequency (cut-off at $0.02 \mathrm{~Hz}$ ) temperature variance scaled with data in panel (b). For reference, temperature contours are given every $0.1{ }^{\circ} \mathrm{C}$ (thin black). (d) Time series of vertically averaged data of panel (e) (turbulence dissipation rate), in comparison with vertically averaged data of panel (c) (arbitrary vertical scale). (e) Turbulence dissipation rate, estimated using Eq. (1). White also indicates values below threshold. For reference, temperature contours are given every $0.1^{\circ} \mathrm{C}$ (thin black). The near-horizontal band at about $\mathrm{z}=-915 \mathrm{~m}$, days $102.22-102.24$ are false dissipation rates due to salinity intrusions (encircled). The arrow indicates turbulent overturning within the interface due to extremely small-scale waves breaking (the waves are also indicated by arrow in panels (a) and (c)). 
too largest overturns are found in the smaller-scale homogeneous layers, e.g., in the first quarter of time in Figure 3. These overturns have a vertical scale of about $10 \mathrm{~m}$, but they have a relatively long duration of 300-600 s. Largest dissipation rates are observed in the upper half of the weakly stratified layer, with local amplifications under interfacial wave crests (e.g., days 102.195-102.20; Figures 3(d) and 3(e)). During such periods, HF-temperature variance is also increased (Figures 3(c) and 3(d)). However, precise timing of peaks in vertical averages may (slightly) differ from those of dissipation rate estimates (Figure 3(d)). In the depth-time domain, largest HF-temperature variance is predominantly found in the interface capping the weakly stratified layer (Figure 3(c)), whereas dissipation rate peaks just below, at the edge or just on the weak stratification side (Figure 3(e)). It is noted that genuine dissipation rates and turbulence variance should be estimated over all turbulence scales, i.e., over approximately the entire vertical range here, as for Figure 3(d).

An anomalously large overturn $(\sim 20 \mathrm{~m})$, the largest in Figure 3, is found below, and just after, a strong nonlinear interfacial wave (day $\sim 102.226$ ). This wave does not incur breaking in the interface itself, but in the weakly stratified layer below. It also seems to generate mixing in moderately stratified layers above, as HF-temperature variance is also increased. Relatively large wave crest phase differences are observed in the depth-time image, and higher up around day 102.23 apparent mode-2 "propagation" is observed, evidence of overturning within an interface. ${ }^{31} \mathrm{HF}-$ temperature variance more than dissipation rate reveals the breaking of a $200 \mathrm{~s}$ long group of very high-frequency waves/overturns in the strong interface capping the large weakly stratified layer: at day 102.232. These are indicated by arrows in Figures 3(a), 3(c), and 3(e).

The one-and-a-half hour and depth mean dissipation rate for Figure 3 amounts $[\langle\varepsilon\rangle]=$ $(2.1 \pm 0.6) \times 10^{-8} \mathrm{~W} \mathrm{~kg}^{-1}$ (and the associated vertical eddy diffusivity $\left[\left\langle\mathrm{K}_{\mathrm{z}}\right\rangle\right]=(4 \pm 1.2) \times$ $\left.10^{-4} \mathrm{~m}^{2} \mathrm{~s}^{-1}\right)$. The two half-hour periods around the larger breaking underneath nonlinear interfacial wave (crests) give depth-time mean values of $[\langle\varepsilon\rangle]=(1.9 \pm 0.6) \times 10^{-8} \mathrm{~W} \mathrm{~kg}^{-1}\left(\left[\left\langle\mathrm{~K}_{\mathrm{z}}\right\rangle\right]=(4 \pm\right.$ $\left.1.2) \times 10^{-4} \mathrm{~m}^{2} \mathrm{~s}^{-1}\right)$ for the period of Figure $4(\mathrm{a})$ and $[\langle\varepsilon\rangle]=(2.3 \pm 0.6) \times 10^{-8} \mathrm{~W} \mathrm{~kg}^{-1}\left(\left[\left\langle\mathrm{~K}_{\mathrm{z}}\right\rangle\right]=\right.$ $\left.(6 \pm 1.5) \times 10^{-4} \mathrm{~m}^{2} \mathrm{~s}^{-1}\right)$ for the period of Figure 4(b). The latter is dominated by the single 20-m large overturn-peak. In contrast, temperature variance shows larger values for Figure 4(a) than for Figure 4(b), except at the buoyancy frequency. This suggests that the lower part of the strongly stratified interface and the upper part of the weakly stratified layer are quite turbulent.

To investigate the relationship between (high-frequency) internal waves and turbulence, the two half-hour periods are analyzed spectrally (Figure 4). The interface reaches a stratification of about $\mathrm{N}_{\mathrm{m}}=8 \times 10^{-3} \mathrm{~s}^{-1}$ (Figure 4(a)) and $1.3 \times 10^{-2} \mathrm{~s}^{-1}$ (Figure 4(b)), while being split between two depths in Figure 4(a). The $\mathrm{N}_{\mathrm{m}}$ indicate a change of spectral slope from about -1 to $-2 \pm$ $1 / 3$ in the $60 \mathrm{~m}$ vertically mean temperature spectra $\left\langle\Phi_{\mathrm{T}}\right\rangle(\sigma)$ (upper panels in Figure 4; scaled by the mean buoyancy frequency). Although it is obvious from Figure 3 that peak-dissipation rate is found underneath the high-frequency interfacial wave of Figure 4(b), the associated half-hour-mean temperature spectrum shows less variance at "turbulence" frequencies $\sigma>\mathrm{N}_{\mathrm{m}}$ (the red slope is identical in both panels), commensurate the difference in temperature variance data.

For a comparison with the vertical mean spectra, the variance ratio $\Phi_{\mathrm{T}} /\left\langle\Phi_{\mathrm{T}}\right\rangle$ is plotted in the lower, color, panels of Figure 4. In these panels it is seen that the $\sim 10 \mathrm{~m}$ vertical-range of the interface has larger variance than the average values at frequencies $\sigma<0.7 \mathrm{~N}_{\mathrm{m}}$, in both cases. In a few $\mathrm{m}$ thinner layers, a small extension of variance from the interface is observed to about $\sigma=$ $2 \mathrm{~N}_{\mathrm{m}}$. In both cases in the layers above the interface, the variance ratio $<1$, except for a particular local buoyancy frequency near the top of the range. In contrast in the layers below the interface, it is seen that uniformly $\Phi_{\mathrm{T}} /\left\langle\Phi_{\mathrm{T}}\right\rangle<1$ for $\sigma<\mathrm{N}_{\mathrm{m}}$. At those depths, for $\sigma>\mathrm{N}_{\mathrm{m}}$ across about $20 \mathrm{~m}$ in the weakly stratified layer, $\Phi_{\mathrm{T}} /\left\langle\Phi_{\mathrm{T}}\right\rangle>1$, with largest values in the upper half of that layer. Also, positive logarithmic variance ratio values are found at progressively higher frequencies $(\sigma>$ $\mathrm{N}_{\mathrm{m}}$ ) the greater the depth. In Figure 4(a), a smooth transition is found between the regions of high variance ratio in the interface at $\sigma<\mathrm{N}_{\mathrm{m}}$ and in the weakly stratified layer at $\sigma>\mathrm{N}_{\mathrm{m}}$. However in Figure 4(b), a consistent band of low variance ratio is observed at about $\mathrm{z}=-930 \mathrm{~m}$, which separates the two layers.

Such a vertical layering in variance ratios is less observed when turbulence overturns are thus large that they push and fold the interface across the entire depth of the weakly stratified layer. This occurred during the second tidal period here (Figures 5-7). With respect to Figure 3, the interface 

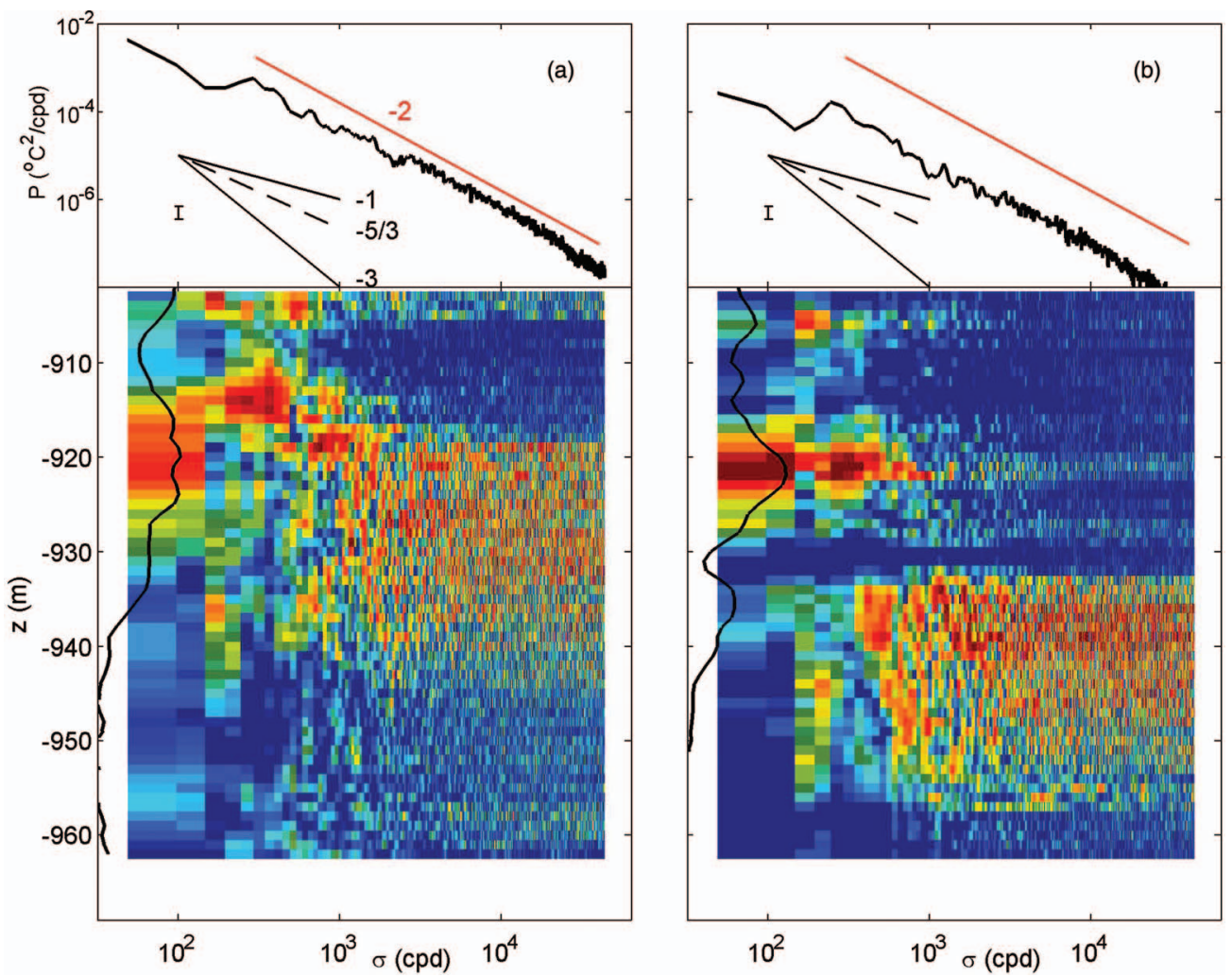

FIG. 4. Spectral evolution of two half hour periods from Figure 3(a), scaled with the local buoyancy frequency. In the lower, coloured depth-frequency panels the temperature variance ratio is given in logarithmic fashion between values of factors $10^{-1}$ (dark-blue) and $10^{+1}$ (dark-red) and with respect to the vertically averaged spectrum of conservative temperature (upper panels in black). The vertical black line in each of the colour panels indicates the local mean N-profile. (a) During the passage of a moderate small-scale internal wave crest. (b) A small interfacial wave around its steepening and turbulence generation in the layer below, the largest dissipation rate in the period of Figure 3. The different slopes are given for reference, the -2 slope specifically for comparing variance.

in this case study is less smooth and more turbulent (Figure 5(a)), whilst the interface-stratification is as intense (Figure 5(b)), albeit somewhat more patchy and variable with time. In Figure 5(a), the near-bottom interface is clearly visible over the case-study period. Overturns cover the entire 30-m vertical-range of the weakly stratified layer, which shows few tilted interfaces (Figures 5(b) and 5(c)). Overturns last about $600 \mathrm{~s}$ and several occur in bands of about half-an-hour duration. The one-and-a-half hour depth-mean $[\langle\varepsilon\rangle]=(1.5 \pm 0.5) \times 10^{-7} \mathrm{~W} \mathrm{~kg}^{-1}\left(\left[\left\langle\mathrm{~K}_{\mathrm{z}}\right\rangle\right]=(4 \pm 1.2) \times\right.$ $\left.10^{-3} \mathrm{~m}^{2} \mathrm{~s}^{-1}\right)$ for the period of Figures 5 and $7(\mathrm{a})$ and $[\langle\varepsilon\rangle]=(3.1 \pm 0.7) \times 10^{-7} \mathrm{~W} \mathrm{~kg}^{-1}\left(\left[\left\langle\mathrm{~K}_{\mathrm{z}}\right\rangle\right]\right.$ $\left.=(6 \pm 1.5) \times 10^{-3} \mathrm{~m}^{2} \mathrm{~s}^{-1}\right)$ for the half-hour period of Figures 6 and 7(b). The latter period is characterized by large (asymmetric) Holmboe overturns and shows details of secondary overturning along the cusped large interface. Largest dissipation rate is observed along that curved interface, most in the upper edge and upgoing part of the wave, e.g., on days 102.708 and 102.714 , and in the weakly stratified core during the first $200 \mathrm{~s}$ of each Holmboe passage, e.g., on day 102.714102.716. These observations are consistent with asymmetric Holmboe instabilities as found in direct numerical simulations, ${ }^{16}$ and as observed in Fraser River estuary. ${ }^{32}$ Here, the first $200 \mathrm{~s}$ of each Holmboe passage show the largest discrepancy between vertical averages of HF-temperature variance and dissipation rate estimates (Figure 6(d)). In depth-time, largest temperature variance is observed along the interface mainly, but more focused on the center of the braid between two Holmboe instabilities (Figure 6(c)). Above the interface patches of overturns/dissipation rate are observed which are just separated from the large-turbulence-area. These patches are best visible at the position of the wave trough, e.g., on day 102.713. Strongest Holmboe-overturning occurs when 


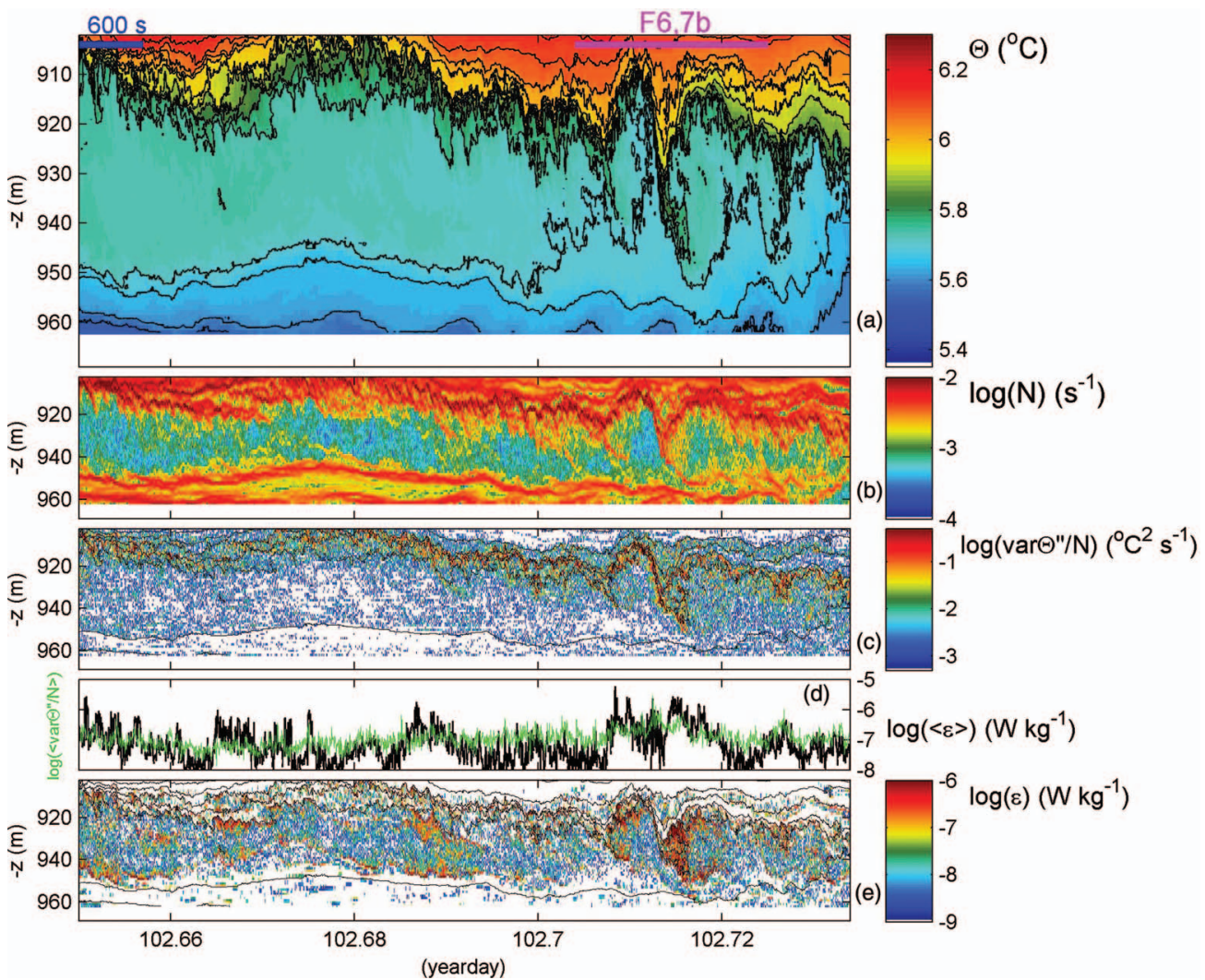

FIG. 5. As Figure 3, but for a detail from the second tidal period, which is a sample with relatively large high-frequency internal wave activity just before the warming phase of the internal tide.

the near-bottom layer is exactly out-of-phase with the interfacial wave motion, as in the period of Figure 6.

During the period of the large overturn in Figure 6, the vertically mean temperature spectrum (Figure 7(b)) is enhanced over all frequencies with respect to the spectra of Figure 4 (one can use the red slope for reference). Also, the -1 slope for $\sigma<\mathrm{N}_{\mathrm{m}}$, "internal wave domain," is merged with the $-2 \pm 1 / 3$ slope at frequencies $\sigma<\mathrm{N}_{\mathrm{m}}$, "turbulence domain." In further contrast with the data in Figure 4, the temperature variance ratio $>1$ is found across more or less the same depth range for both interfacial wave frequencies $\sigma<\mathrm{N}_{\mathrm{m}}$ and turbulence frequencies $\sigma>\mathrm{N}_{\mathrm{m}}$ in Figure 7. This suggests turbulence adopts the same full scales as the interfacial wave height. As individual $\mathrm{N}_{\mathrm{m}}$-profiles (dashed lines in Figure 7(b)) show the small density-interface extent of a few meters, the mean buoyancy frequency profiles show them smeared over a much larger range of $\sim 20 \mathrm{~m}$. This smearing is due to the interfacial wave motions, but, when limited by the thickness of the large-scale (internal tidal) shear layer, thus allows for asymmetric Holmboe-waves to develop since the thickness ratio of shear over density interface $>1.4$.

\section{DISCUSSION}

The presented case studies of internal-wave-induced stratified turbulence in the deep ocean are related to the transition from the up- to the downslope phase of an internal tide. Although turbulence is associated with internal wave motions at frequencies near the local buoyancy frequency, the coupling with the internal tide moving up and down the sloping bottom is evident. As the turbulence occurs some distance off the bottom it is not related to (tidal) bottom friction. It also does not influence the resuspension of material from the bottom, but it may affect the transport (further) into the interior. 


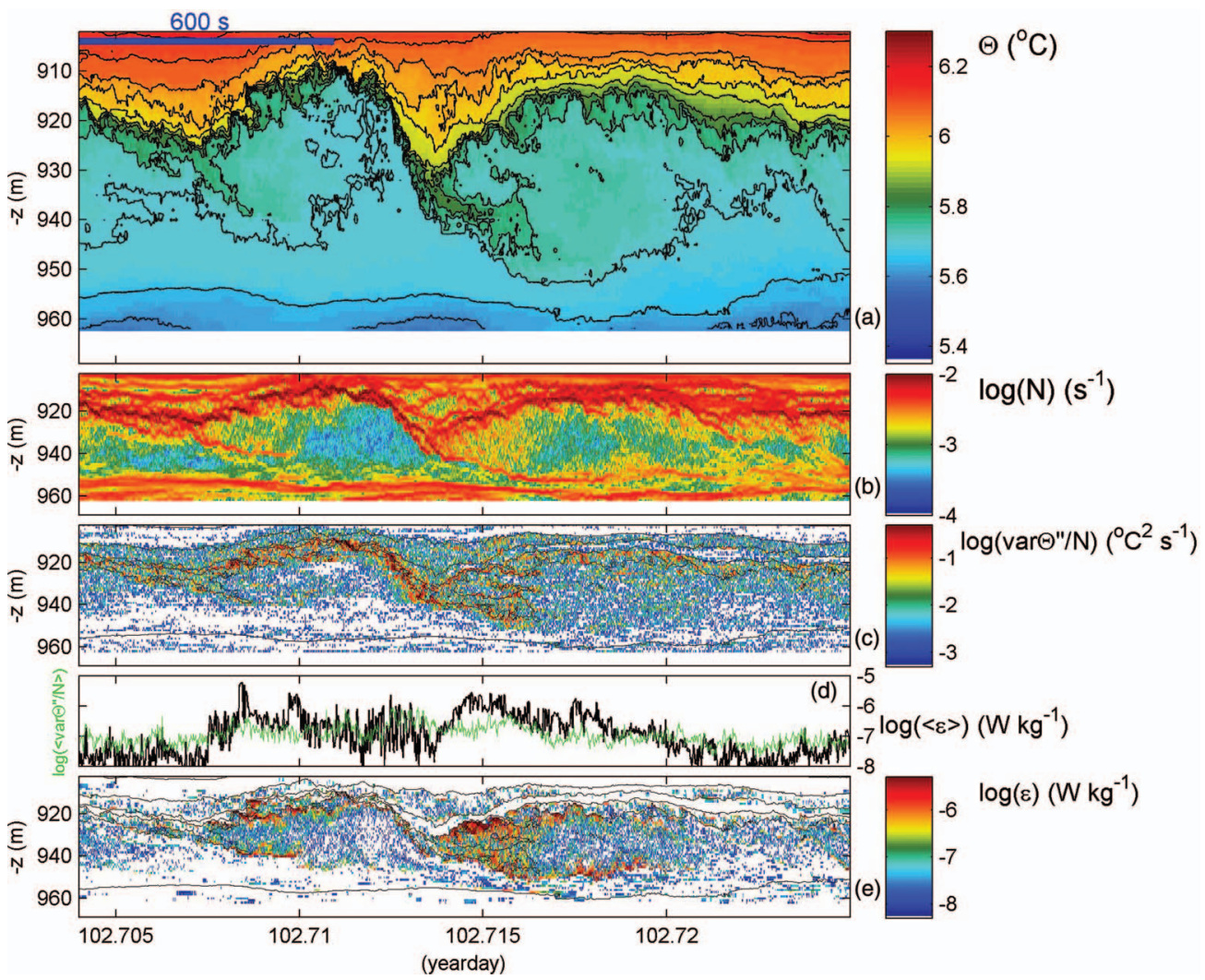

FIG. 6. Half-hour detail from Figure 5, showing asymmetric Holmboe wave overturning in some detail, including secondary overturns along the edge of the large overturn. These are especially visible in scaled temperature variance data (panel (c)), which highlight different parts of the braided structure in comparison with the dissipation rate (panel (e)).

The change of phase of the internal tide is associated with a vertical current shear away from the sea floor. Together with the high-frequency interfacial waves, turbulence is produced in the surrounding weaker stratified layers, with peaks at and just below the strongest interface. The turbulence may be generated indirectly via rather small-amplitude nonlinear interfacial waves that create overturns which are much larger than the interfacial wave-height (Figures 3 and 4). Naturally they cannot produce overturns larger than their height in their own interface; they can only generate these in weaker stratified layers (best example: Figure 4(b)).

Maximum turbulence is generated when the interfacial wave amplitude grows up to the thickness of weakly stratified layers above and below (Figures 5 and 6(b)). Following stratified North Sea observations, ${ }^{33}$ this associates with maximum amplitude growth of the interfacial wave to match the thickness of the shear interface created by the large-scale internal wave, in this case by the tide and apparently $30 \mathrm{~m}$ thick. The produced large overturns (Figure 5(c)) resemble those from KelvinHelmholtz billows produced in laboratories. ${ }^{34}$ However, those billows were generated from the classic roll-up of an interface in a tilted tank experiment. The form of the present large high-frequency internal wave and the deformation in the weakly stratified layer below more resembles a Holmboe instability, ${ }^{15,35}$ even though being very asymmetric. ${ }^{16}$ Apparently in the present observations, this instability develops similar amount of turbulence as Kelvin-Helmholtz shear induced turbulence. Following modeling results ${ }^{15}$ this implies ample time for asymmetric Holmboe instabilities to grow and to be effective. The observations of $25 \mathrm{~m}$ high asymmetric Holmboe overturning may be useful for further modeling studies on the development of high Reynolds number flows like generally found in the ocean, notably where internal waves break above varying bottom topography. Our future work will include a more elaborate comparison between (turbulence) temperature variance and overturn-determined dissipation rate estimates. 

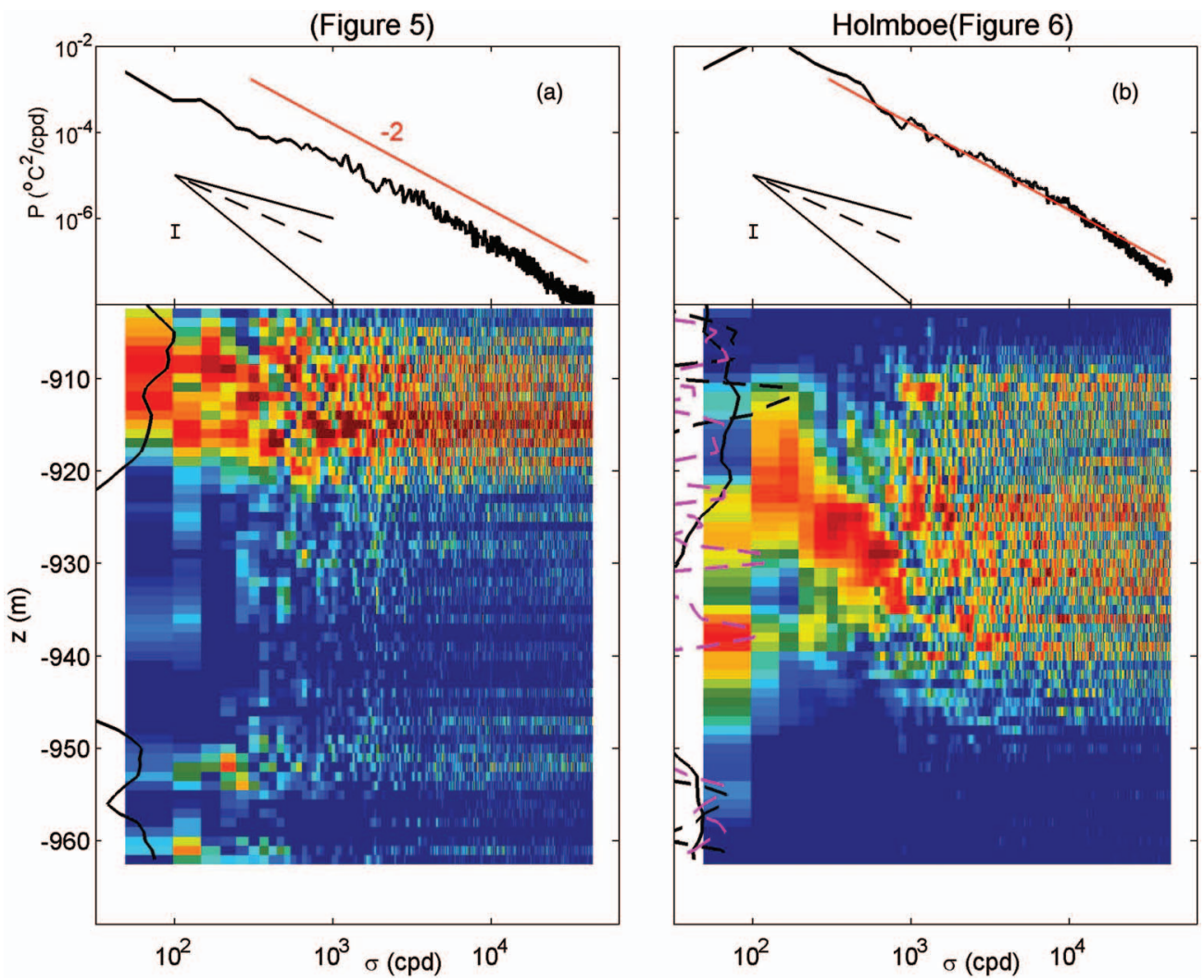

FIG. 7. As Figure 4, but for the periods of Figures 5 and 6: a very large interfacial overturning and penetration in the layer below. The spectral slopes are identical to the ones in Figure 4. In panel (b), the dashed vertical profiles are instantaneous buoyancy frequency profiles for days 102.7114 (just prior to the arrival of the largest overturn; black) and 102.7134 (during the largest overturn penetrating in the weakly stratified layer; purple).

\section{ACKNOWLEDGMENTS}

Jens Greinert and captain and crew of R/V Sonne are acknowledged for deployment and recovery of the mooring. I greatly thank Martin Laan for design and construction of NIOZ temperature sensors and assistance in mooring preparation.

${ }^{1}$ M. C. Gregg, "Scaling turbulent dissipation in the thermocline," J. Geophys. Res. 94, 9686, doi:10.1029/JC094iC07p09686 (1989).

${ }^{2}$ G. O. Marmorino, L. J. Rosenblum, and C. L. Trump, "Fine-scale temperature variability: the influence of near-inertial waves," J. Geophys. Res. 92(13), 13049, doi:10.1029/JC092iC12p13049 (1987).

${ }^{3}$ J. M. Klymak, M. Buijsman, S. M. Legg, and R. Pinkel, "The direct breaking of internal waves at steep topography," Oceanography 25, 150 (2012).

${ }^{4}$ H. van Haren and L. Gostiaux, "Large internal waves advection in very weakly stratified deep Mediterranean waters," Geophys. Res. Lett. 38, L22603, doi:10.1029/2011GL049707 (2011).

${ }^{5}$ K. L. Polzin, K. G. Speer, J. M. Toole, and R. W. Schmitt, "Intense mixing of Antarctic Bottom Water in the equatorial Atlantic Ocean," Nature (London) 380, 54 (1996).

${ }^{6}$ W. Munk, “Abyssal recipes," Deep-Sea Res. 13, 707 (1966).

${ }^{7}$ L. Armi, "Some evidence for boundary mixing in the deep ocean," J. Geophys. Res. 83, 1971, doi:10.1029/JC083iC04p01971 (1978).

${ }^{8}$ C. Garrett, "The role of secondary circulation in boundary mixing," J. Geophys. Res. 95, 3181, doi:10.1029/JC095iC03p03181 (1990).

${ }^{9}$ S. A. Thorpe, "Current and temperature variability on the continental slope," Philos. Trans. R. Soc. London, Ser. A 323, 471 (1987).

${ }^{10}$ H. van Haren, M. Laan, D.-J. Buijsman, L. Gostiaux, M. G. Smit, and E. Keijzer, "NIOZ3: independent temperature sensors sampling yearlong data at a rate of $1 \mathrm{~Hz}$, , IEEE J. Ocean. Eng. 34, 315 (2009).

${ }^{11}$ H. van Haren and L. Gostiaux, "Detailed internal wave mixing above a deep-ocean slope," J. Mar. Res. 70, 173 (2012). 
${ }^{12}$ J. N. Moum, D. M. Farmer, W. D. Smyth, L. Armi, and S. Vagle, "Structure and generation of turbulence at interfaces strained by internal solitary waves propagating shoreward over the continental shelf," J. Phys. Oceanogr. 33, 2093 (2003).

${ }^{13}$ W. R. Geyer, A. C. Lavery, M. E. Scully, and J. H. Trowbridge, "Mixing by shear instability at high Reynolds number," Geophys. Res. Lett. 37, L22607, doi:10.1029/2010GL045272 (2010)

${ }^{14}$ W. R. Geyer and J. D. Smith, "Shear instability in a highly stratified estuary," J. Phys. Oceanogr. 17, 1668 (1987).

${ }^{15}$ W. D. Smyth and K. B. Winters, "Turbulence and mixing in Holmboe waves," J. Phys. Oceanogr. 33, 694 (2003).

${ }^{16}$ J. R. Carpenter, G. A. Lawrence, and W. D. Smyth, "Evolution and mixing of asymmetric Holmboe instabilities," J. Fluid Mech. 582, 103 (2007).

${ }^{17}$ S. A. Thorpe, "A method of producing a shear flow in a stratified fluid," J. Fluid Mech. 32, 693 (1968).

${ }^{18}$ G. A. Lawrence, F. K. Browand, and L. G. Redekopp, “The stability of a sheared density interface," Phys. Fluids A 3, 2360 (1991).

${ }^{19}$ H. van Haren and J. Greinert, "Variability of internal frontal bore breaking above Opouawe Bank methane seep area (New Zealand)," Geochem. Geophys. Geosys. 14, 2460, doi:10.1002/ggge.20170 (2013).

${ }^{20}$ K. Faure, J. Greinert, J. S. von Deimling, D. F. McGinnis, R. Kipfer, and P. Linke, "Methane seepage along the Hikurangi Margin of New Zealand: Geochemical and physical evidence from the water column, sea surface and atmosphere," Mar. Geol. 272, 170 (2010).

${ }^{21}$ P. Linke, S. Sommer, L. Rovelli, and D. F. McGinnis, "Physical limitations of dissolved methane fluxes: the role of bottom-boundary layer processes," Mar. Geol. 272, 209 (2010).

${ }^{22}$ T. J. McDougall, R. Feistel, F. J. Millero, D. R. Jackett, D. G. Wright, B. A. King, G. M. Marion, C.-T. A. Chen, and P. Spitzer, "Calculation of the thermodynamic properties of seawater, global ship-based repeat hydrography manual," IOCCP Report 14, ICPO Publication Series 134 (U.N.E.S.C.O., Paris, 2009).

${ }^{23}$ TEOS, 2010, see http://www.teos-10.org/.

${ }^{24}$ S. A. Thorpe, "Turbulence and mixing in a Scottish loch," Philos. Trans. R. Soc. London, Ser. A 286, 125 (1977).

${ }^{25}$ P. S. Galbraith and D. E. Kelley, "Identifying overturns in CTD profiles," J. Atmos. Ocean. Tech. 13, 688 (1996).

${ }^{26}$ T. M. Dillon, "Vertical overturns: a comparison of Thorpe and Ozmidov length scales," J. Geophys. Res. 87, 9601, doi:10.1029/JC087iC12p09601 (1982).

${ }^{27}$ T. R. Osborn, "Estimates of the local rate of vertical diffusion from dissipation measurements," J. Phys. Oceanogr. 10, 83 (1980).

${ }^{28}$ N. S. Oakey, "Determination of the rate of dissipation of turbulent energy from simultaneous temperature and velocity shear microstructure measurements," J. Phys. Oceanogr. 12, 256 (1982).

${ }^{29}$ C. Wunsch, "Internal tides in the ocean," Rev. Geophys. Space Phys. 13, 167, doi:10.1029/RG013i001p00167 (1975).

${ }^{30}$ H. van Haren and L. Gostiaux, "Energy release through internal wave breaking," Oceanography 25, 124 (2012).

${ }^{31}$ R. E. Davis and A. Acrivos, "Solitary internal waves in deep water," J. Fluid Mech. 29, 593-607 (1967).

${ }^{32}$ E. W. Tedford, J. R. Carpenter, R. Pawlowicz, R. Pieters, and G. A. Lawrence, "Observation and analysis of shear instability in the Fraser River estuary," J. Geophys. Res. 114, C11006, doi:10.1029/2009JC005313 (2009).

${ }^{33}$ H. van Haren, "Internal waves near the buoyancy frequency in a narrow wave-guide," J. Sea Res. 53, 121 (2005).

${ }^{34}$ M. D. Patterson, C. P. Caulfield, J. N. McElwaine, and S. B. Dalziel, "Time-dependent mixing in stratified Kelvin-Helmholtz billows: experimental observations," Geophys. Res. Lett. 33, L15608, doi:10.1029/2006GL026949 (2006).

${ }^{35}$ W. D. Smyth, "Secondary circulations in Holmboe waves," Phys. Fluids 18, 064104 (2006).

${ }^{36}$ A. Cimatoribus, personal communication (2013). 